\title{
Effectiveness of acupuncture and moxibustion compared with electroacupuncture and moxibustion in older people with gonarthrosis
}

\author{
Enachescu M.F. ${ }^{1}$ \\ ${ }^{1}$ Fisioterapeuta, Residència “Sagrat Cor”, Benavent de Segrià, Lleida, \\ Spain
}

Rev Fisioter Invasiva 2019;2:88.

\begin{abstract}
Keywords

- acupuncture

- electroacupuncture

- moxibustion

- gonarthrosis

Background Gonarthrosis is a subtype of arthrosis which produces greater functional disability in our context. Women are more affected, with a prevalence in the general population of $16 \%$ and a clear increase as age advances, reaching up to $43 \%$.

Aims To evaluate whether the combined treatment of electroacupuncture and moxibustion is more effective than the treatment of acupuncture and moxibustion in patients of advanced age with gonarthrosis.

Material and Methods An experimental, prospective and randomized study. Patients were divided into two groups: group $A$, who received acupuncture $(n=6)$ and group EA who received electroacupuncture $(n=7)$ : modulated TENS $(F=5 \mathrm{~Hz}, P=50 \mu \mathrm{S}$, $I=90 \%, 10 \mathrm{~min})$. Both group $A$ and $E A$ combined treatments with moxibustion. Three interventions were performed, over three consecutive weeks, and the results obtained in each group were compared using several validated scales.

Results $84.6 \%$ of patients were women, with a mean age of 83.3 years, and $53.8 \%$ of these with obesity. The right leg was the more affected (76.9\%) and $46.2 \%$ had a severe disability. Pain reduction (Visual Analog Scale) was statistically significant in each session in both groups however, to a greater extent in group EA (reduction of pain EA 3.4 versus 1.3 in A). The improvements of stiffness with both treatments was evident (mean 69.2\%), however without statistically significant between-group differences. A clear difference was not found in the functionality according to the different scales applied (WOMAC, Barthel, Katz, Up\&Go) nor in the reduction in the use of medication. Conclusion The results obtained show a clear improvement in the control of pain and rigidity with the combination of both therapies, although differences were not found in the functionality and muscle strength scales, which are values that we believe would improve with a greater sample and a greater duration of interventions. In conclusion, in our study, electroacupuncture combined with moxibustion provides slightly better results to acupuncture combined with moxibustion, regarding the improvement of pain and stiffness in older patients with gonarthrosis.
\end{abstract}

DOI https://doi.org/ $10.1055 / \mathrm{s}-0039-3401868$ ISSN 2386-4591.
Copyright @ 2019 by Thieme Revinter Publicações Ltda, Rio de Janeiro, Brazil
License terms 